Supplemental Materials

\title{
Qualitative and Quantitative Changes to E. coli During Treatment with Magainin 2 Observed in Native Conditions by Atomic Force Microscopy
}

\author{
Kanesha Overton ${ }^{1+}$, Helen M. Greer ${ }^{1+}$, Megan A. Ferguson², Eileen M. Spain ${ }^{3}$, Donald E. \\ Elmore ${ }^{4}$, Megan E. Núñez ${ }^{4}$, and Catherine B. Volle*\#
}

1 Department of Biology, Cottey College, Nevada, MO 64772, ${ }^{2}$ Department of Chemistry, State University of New York, New Paltz, NY 12561, ${ }^{3}$ Department of Chemistry, Occidental College, Los Angeles, CA 90041, ${ }^{4}$ Department of Chemistry and Program in Biochemistry, Wellesley College, Wellesley, MA 02481.

+ These authors contributed equally to this work.

\# Current address: Departments of Biology and Chemistry, Cornell College, Mount Vernon, IA 52314.

* To whom correspondence should be addressed:

cvolle@cornellcollege.edu

phone: 319-895-4413

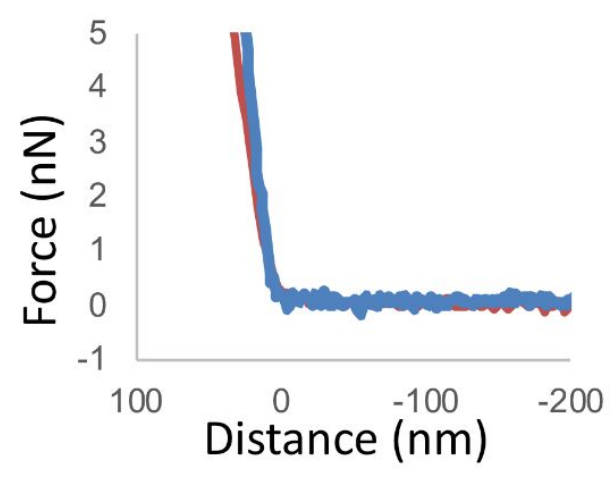

Supplementary Figure 1: Free MAG2 does not substantially affect the behavior of the tip. Force curves were acquired off the cells, on the surrounding glass substrate, during experiments. Representative control force curves from an experiment where MAG2 was present (red) or absent (blue) are shown. 


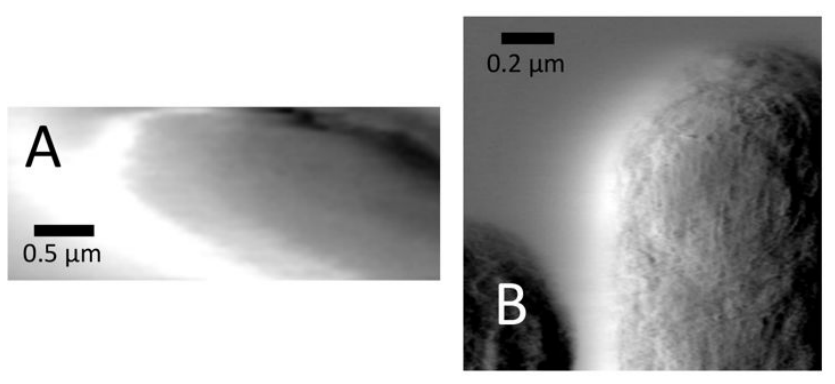

Supplementary Figure 2: amplitude images of planktonic E. coli cells captured by AFM. Cells were imaged at 15 (panel A) and 30 (panel B) minutes. 